* Doutor em Direito Constitucional nas Relações Privadas pela Universidade de Fortaleza (UNIFOR). PósDoutorado em Direito na Universidade de Fortaleza. Pós-Doutorando em Direito pela Universidade Católica de Pernambuco (UNICAP). Professor da Unifanor/Wyden e Unicatólica de Quixadá/CE. E-mail: saulonunes@hotmail. com

\section{Inteligência Artificial, Robótica E O Lado Oculto \\ DE UM Futuro SEM EMPREgos: O INESPERADO Papel da Tributação de Robôs À luz Da Análise EConômica Do Direito}

\begin{abstract}
ARTIFICIAL INTELLIGENCE, ROBOTICS AND THE HIDDEN SIDE OF A FUTURE WITHOUT JOBS: THE UNEXPECTED ROLE OF ROBOT TAXATION IN THE LIGHT OF ECONOMIC ANALYSIS OF LAW
\end{abstract}

\section{Saulo Nunes de Carvalho Almeida*}

Como citar: ALMEIDA, Saulo Nunes de Carvalho. Inteligência artificial, robótica e o lado oculto de um futuro sem empregos: o inesperado papel da tributação de robôs à luz da análise econômica do direito. Scientia Iuris, Londrina, v. 25, n. 1, p. 2948, mar. 2021. DOI: 10.5433/2178-8189.2021v25n1p29. ISSN: 2178-8189.

Resumo: Trata-se de um ensaio que tem por objetivo nuclear investigar as inovações tecnológicas, e seus impactos na automação dos trabalhos, sob as lentes da Análise Econômica do Direito. A pretensão científica desse estudo está na necessidade de introduzir uma nova e complexa questão ao debate, ainda embrionário, acerca da Quarta Revolução Industrial e como os arranjos jurídicos existentes se adequam a esse novo modelo de organização econômica. $\mathrm{O}$ procedimento metodológico que norteou o desenvolvimento desse artigo foi descritivo e exploratório, composto por uma análise jurídico-dogmática, estruturada em pesquisa bibliográfica e documental adotada com o intuito de promover uma compreensão precisa dos institutos jurídicos e econômicos analisados. A pesquisa evidenciou que, por uma perspectiva da regra tributária e da teorização do law and economics, a automação do trabalho torna-se de realização inevitável, pois significa, em especial, a possibilidade de deslocar toda uma vasta cadeia de incidência tributária, suprimindo o fato gerador que ocorreria se o mesmo trabalho tivesse sido realizado por um trabalhador humano. Ou seja, a adoção de um comportamento de desoneração é racional frente aos incentivos jurídicos existentes, desaguando em um resultado econômico eficiente. Nesse sentido, restou concluído que, caso não ocorra uma remodelagem de nossos arranjos normativos, o futuro próximo será marcado pela ampliação do fenômeno da automação acompanhado de uma tendência ao esvaziamento dos direitos 
sociais laborais.

Palavras-chaves: Análise econômica do direito. Imposto de robôs. Tributação da automação. Tributação 4.0.

Abstract: This is an essay that has its nuclear objective the investigation of technological innovations, and their impacts on the automation of jobs, under the lens of Law and Economics. The intention of this study is to introduce a new and complex question to the debate, still embryonic, about the Fourth Industrial Revolution and how the existing legal arrangements are adapted to this new model of economic organization. The methodological procedure that guided the development of this article was descriptive and exploratory, composed of a legal-dogmatic analysis, structured in bibliographic and documentary research to promote a precise understanding of surrounding legal and economic institutions. This research showed that, from the perspective of the tax rule and the theorization of law and economics, the automation of work becomes an inevitable event, which will, possibly, displace an entire vast chain of taxation, suppressing this triggering event that would have occurred if the same work had been carried out by a human worker. In other words, the adoption of exemption behavior is rational in view of existing legal incentives, resulting in an efficient economic result. In this sense, it remains to be concluded that, if there is no remodeling of our normative arrangements, the near future will be marked by the expansion of the automation phenomenon accompanied by a tendency to empty social labor rights.

Keywords: Economic Analysis of law. Taxation of robots. Taxes on automation. Taxation 4.0. 


\section{INTRODUÇÃO}

Os avanços globais da economia digital, em que empresas se tornaram voláteis e operam sem apego a fronteiras ou nacionalidades, apresentam um novo e fértil campo para intelectuais e estudiosos dos mais distintos campos, incluindo o Direito e, mais especificamente, suas ramificações fiscais e tributárias. Aparenta ser inquestionável a urgência de reinventar conceitos tradicionais e políticas fiscais até então atreladas a elementos tangíveis e de simples identificação, como o caminho para tributar uma nova e crescente realidade da indústria, mercado e sociedade. Uma realidade que desafia a criatividade de pesquisadores e acadêmicos, e tira o sono do Fisco, que encontra cada vez mais empecilhos em identificar tributos incidentes, as formas de fiscalizálos e cobrá-los.

Nesse novo modelo econômico (Indústria 4.0), aspectos como renda, trabalho e consumo foram drasticamente impactados com o exponencial crescimento da economia digital, resultando em múltiplos diagnósticos que evidenciam a inadequação das regras tributárias tradicionais. Essa crise não experimentará uma resolução natural, pelo contrário. É razoável argumentar que, sem uma renovação da dogmática jurídica, o ciclo de evolução da tecnologia moderna trará um impacto ainda maior, em especial com o avançar na difusão tecnológica em setores como robótica e inteligência artificial.

Por outro lado, sabe-se que as leis que governam o campo da economia, diferente das leis da física, são feitas pelo homem. Essas dependerão das escolhas de uma sociedade e do comportamento de seus cidadãos. Justamente por isso não é incomum argumentar que a Economia pode ser descrita como uma ciência que estuda o comportamento humano (economia comportamental). Partindo desse pressuposto, a pesquisa buscará enfrentar, entre outros aspectos, o seguinte questionamento: À luz dos pressupostos teóricos da Análise Econômica do Direito (Law and Economics), a função indutora da norma tributária pode ser utilizada como ferramenta de incentivos para trazer concretude à garantia constitucional de proteção do trabalhador em face da automação?

Pretende-se analisar, por uma perspectiva da dogmática da Análise Econômica do Direito (AED), as decisões realizadas pela empresa entre automação do trabalho e manutenção dos postos de emprego, bem como compreender os incentivos existentes que resultam em tais decisões. A proposta buscará evidenciar que há sólidos fatores econômicos e tributários que justificam a racionalidade dos agentes econômicos em enxugarem sua folha de pagamento, e com isso os postos formais de trabalho, para investirem em processos tecnológicos de automação laboral.

Preliminarmente, adequado esclarecer dois relevantes aspectos: primeiro que o raciocínio que será apresentado estará delimitado à uma análise do presente e futuro da automação laboral à luz das teorizações da AED. Isso não deve ser compreendido por uma presunção de irrelevância quanto aos reflexos desse processo nos demais segmentos científicos (jurídicos ou não). A intenção 
dessa delimitação é, tão somente, evitar tentações em adentrar linhas de raciocínios em outros campos que, apesar de sua inquestionável relevância, resultaria em uma digressão da verificação inicialmente proposta. Quanto ao segundo, enfatiza-se que o ensaio ora apresentado certamente ainda se encontra em fase embrionária, sendo necessária a continuidade de estudos, em especial em campos como economia e políticas públicas, capazes de eventualmente configurar a teorização ora posposta em modelos e equações formais.

Para conferir melhor lógica ao ensaio, adequado esclarecer o trajeto o qual o mesmo propõe adotar. Como opção teórico-metodológica, a exposição da matéria ocorrerá na forma de três seções. Na primeira seção deste ensaio, será analisado o avançar da chamada quarta revolução industrial e, em especial, o impacto que a consolidação de uma economia digital possui sobre os postos de trabalho, bem como sua influência sobre os níveis de desigualdades sociais e econômicas. Em seguida, na segunda seção adentraremos a teorização de Coase, e os pressupostos avançados por Willianson, para extrair importantes correlações com esse novo modelo econômico emergente. Por fim, na seção conclusiva será apresentado o método de releitura jurídica de Análise Econômica do Direito, buscando analisar aspectos como escassez de recursos, racionalidade dos agentes e resposta aos incentivos como fundamentos para a adoção da função extrafiscal da norma tributária.

Por óbvio que qualquer radical alteração do desenho tributário envolverá questões complexas e interdisciplinares que precisarão ser consideradas com o maior rigor e planejamento possível. Um desses aspectos diz respeito à teorização que envolve as interações entre Direito e Economia, e como a tomada de decisões dos contribuintes podem influenciar a definição de políticas públicas, de forma a minorar ao invés de agravar a problemática apresentada.

\section{REVOLUÇÃO INDUSTRIAL 4.0}

AQuarta Revolução Industrial ${ }^{1}$, também chamada de Revolução Industrial 4.0, corresponde a nova fase experimentada pelo processo de industrialização e a mudança de paradigmas que esse desenvolvimento tecnológico vem progressivamente introduzindo na sociedade. A expressão engloba distintas tecnologias emergentes, tais como troca de dados complexos, inteligência artificial integrada e processos de automação sofisticados. É a transição para um sistema de infraestrutura oriundo da revolução digital ("fábrica inteligente").

Um cenário que já está modificando, em ritmo acelerado, a forma como vivemos, nos comunicamos, como trabalhamos e consumimos e, até mesmo, como nos relacionamos (SCHWAB, 2016). Essa revolução da indústria trouxe a fusão entre os mundos físicos e digitais, comércio e economia, dando ensejo a diversas novas modalidades de negócios, como subscrição

1 A expressão Revolução Industrial 4.0 parte do pressuposto histórico do reconhecimento de três períodos industriais anteriores: $1^{\circ}$ Revolução Industrial (séc. XVIII) modificação do processo artesanal para a inserção das primeiras máquinas capazes de acelerar o processo de produção; $2^{\circ}$ Revolução Industrial (meados séc. XIX) surgimento das primeiras linhas de montagem, protagonismo da eletricidade e petróleo, desenvolvimento de tecnologias como avião, telefones, refrigeradores; $3^{\circ}$ Revolução Industrial (meados do séc. XX): introdução da tecnologia da informação e dos primeiros computadores, revolucionando todas as áreas do conhecimento. 
de serviços de streaming, e-commerce, computação em nuvem ("cloud computing”), internet das coisas, impressão 3D, moedas virtuais, plataformas de mercados ("marketplace"), softwares de automação, robotização apenas para citar alguns dos negócios disruptivos envolvendo mercadorias corpóreas e incorpóreas que estão transformando radicalmente nossa sociedade e economia.

Uma realidade que foge de qualquer equivalência histórica. Por exemplo, quão paradoxal é saber que a maior rede de hotéis do mundo não possui nenhum quarto de hotel $\left(\right.$ Airbnb $\left.^{2}\right)$, que a maior empresa de transporte do mundo não possui veículos ou frota de carros $\left(\right.$ Uber $\left.^{3}\right)$ e que o gigante do varejo internacional não possui produtos em seu estoque (Alibaba ${ }^{4}$ ). Essas, e muitas outras empresas similares, dividem um modelo de organização pautado no uso de tecnologias para aproximar partes e facilitar transações de modo remoto.

Veja, por exemplo, o impacto que um único aplicativo como o WhatsApp trouxe sobre todo o setor de telefonia do país (e do mundo). Utilizando a internet e aparelhos celulares para a comunicação, muitos dos seus usuários passaram a adotar a ferramenta ao invés das ligações tradicionais. O aplicativo praticamente extinguiu uma das principais fontes de receitas da indústria, as trocas de SMS, vendidas na forma de pacotes ou cobradas individualmente. Esse novo comportamento do consumidor, em face da mudança digital, impactou não apenas a arrecadação das empresas do setor, mas, por consequência, significou uma queda na arrecadação fiscal incidente sobre o segmento de telefonia ${ }^{5}$.

Um modelo econômico marcado pela circulação de mercadorias digitais, em que transações ocorrem no ambiente virtual, e que possibilitam empresas a se fazerem presente em múltiplas nações mesmo sem possuir estabelecimento físico em nenhuma delas. Uma realidade de mercados que transacionam ativos inatingíveis pela tributação, de mercantilização de dados pessoais, de facilidade de fluxo de capitais e de uma economia em constante mutação. Evidenciando esse novo cenário, basta olharmos para o prestigiado ranking da Forbes de empresas mais valiosas do mundo (BADENHAUSEN, 2019). As marcas que ocupam às cinco primeiras colocações são respectivamente: Apple, Google, Microsoft, Amazon e Facebook. Todas do segmento tecnológico. Gigantes digitais que concentram riquezas capazes de superar o Produto Interno Bruto (PIB) de muitas nações, evidenciando o cenário de transformações radicais em curso. Um novo sistema econômico que invariavelmente desperta, reflexões no campo da equidade, justiça e proteção social.

Nesse mundo cada vez mais digital e conectado, a única certeza entre os especialistas é que o atual modelo tributário vigente aparenta ser inadequado ou insuficiente para responder a essa realidade. Estudos começam a emergir evidenciando a imperatividade de uma reformulação nas regras jurídicas, tornando-as capazes de sanar possíveis distorções comerciais existentes e, ao

2 Plataforma de hospedagem alternativa, sediada em São Francisco, desenvolvida em 2008. Atualmente, disponível em mais de 190 países ao redor do mundo, está avaliada em U\$ 30 bilhões.

3 Fundada em 2009 e, em maio de 2019, foi avaliada em U\$ 82,4 bilhões.

4 Grupo chinês de comércio pela internet e pagamentos online.

5 O Brasil é um dos países do mundo que possui maior carga tributária sobre telefonia. São tributos incidentes sobre a receita bruta do setor de telecomunicações, tributos incidentes sobre estações e terminais, entre outros que, somados, significam um total de 29,2\% do valor da conta telefônica (TELECO, 2020). 
mesmo tempo, não resultar em entraves ao desenvolvimento econômico e social do país.

Todavia, para fins da pesquisa ora em desenvolvimento, a preocupação acerca do necessário aperfeiçoamento do sistema tributário para responder a Quarta Revolução Industrial se limitará a uma única questão, a proteção do trabalhador em face da automação. Essa preocupação, melhor exposta nos tópicos que seguem, pode ser sintetizada pelo movimento iniciado nos últimos anos de desconstrução das relações formais de trabalho mediante o sensível crescimento da chamada economia compartilhada (plataformas como Uber, Rappi, iFood, e muitos outros), e que podem ser agravadas com a chegada da economia digital e o processo de automação dos trabalhos.

\subsection{Economia digital e o futuro do emprego}

Inicialmente, é tentador acreditar que a preocupação com o futuro do trabalho face à automação é hiperbólica. Afinal, certas categorias de trabalhos sempre foram reduzidos ou eliminados pela evolução tecnológica. Máquinas substituem trabalhos humanos desde a Revolução Industrial. Historicamente, é possível afirmar que os benefícios dessa inserção tecnológica na economia sempre superaram os malefícios do desemprego setorial. Afinal, a aplicação da tecnologia nos setores produtivos simplesmente foi acompanhada de um processo de migração dos trabalhadores para novos campos (HARARI, 2015).

Entretanto, um corpo cada vez mais expressivo de pesquisas tem levado a crer que o que se experimentará com os avanços da chamada quarta revolução industrial será um cenário sem precedentes históricos. Estudos indicam que a expansão de setores como Automação de Processos Robóticos (RPA), Inteligência Artificial, Operação de Dados (DataOps), Softwares de Automação, Machine Learning ${ }^{6}$, Deep Learning ${ }^{7}$ e muitos outros fenômenos, quando aplicados à automação laboral, poderão alcançar consequências singulares em dimensões econômicas, sociais, fiscais e culturais do país ${ }^{8}$.

Pesquisa desenvolvida pelo Laboratório do Futuro (UFRJ) intitulado "O futuro do emprego no Brasil: Estimando o Impacto da Automação", analisou mais de 2.500 ocupações que englobavam desde trabalhos manuais e repetitivos até trabalhos portadores de elevado grau de especialização, e chegaram à preocupante conclusão que até $60 \%$ desses ofícios poderão experimentar graves impactos pela automação nas próximas décadas ("probabilidade de automação maior do que $70 \% "$ ). Estudo similar, desenvolvido pela McKinsey Global Institute (UNIVERSIDADE FEDERAL DO RIO DE JANEIRO, 2019), concluiu que mais de 50\% das ocupações do Brasil já poderiam ser automatizadas utilizando tão somente a tecnologia atualmente

6 É um ramo da inteligência artificial que introduz método de análise de dados em que modelos analíticos são construídos para possibilitarem que sistemas possam identificar determinados padrões, "aprender" com tais dados e reutilizá-los para tomar decisões.

7 Processo que desenvolve parâmetros básicos que permite ao computador reconhecer padrões e realizar tarefas similares aos seres humanos.

$8{ }^{9}$ Essa certamente não é uma problemática experimentada unicamente pelo Brasil. Pelo contrário. Com o crescimento da robótica e inteligência artificial, a econômica digital produzirá sensível impacto sobre as relações de trabalho em todo o mundo. No entanto, para fins de delimitação do objeto de estudo, o presente ensaio limita-se a uma análise 9 doméstica de suas consequências. 
disponível. Por fim, pode-se destacar também pesquisa desenvolvida na UNB, pelo Laboratório de Aprendizado de Máquina em Finanças e Organizações (LAMFO, 2019), que chegou a conclusão que mais da metade (54\%) dos empregos formais do Brasil estão ameaçados de serem substituídos por "máquinas" até o ano de 2026.

Qualquer proximidade factual com as previsões acima significaria não apenas um cenário de desemprego em massa ${ }^{10}$, mas também de sensível alargamento dos já elevados níveis de desigualdades sociais e econômicas ${ }^{11}$. Isso porque os resultados indicam que os trabalhos mais suscetíveis à automação são aqueles que marcados pelo baixo nível de especialização, presentes em setores eminentemente ocupados pela população de classe baixa e média, como produção, serviços e comércio. São milhares de motoristas, atendentes de caixas, profissionais de setores administrativos, comerciantes, assistentes, funcionários de call center, corretores, entre diversas outras profissões consideradas pelos especialistas como "extremamente vulneráveis" a automação.

Para esses segmentos, o prognóstico não é apenas de desemprego em massa, mas também de sensível aumento da precariedade laboral. Afinal, os trabalhos que serão mantidos, nesses setores mais vulneráveis a automação, para que possam se tornar economicamente competitivos, experimentarão significativas quedas salariais, bem como o esvaziamento de múltiplos direitos sociais e trabalhistas ${ }^{12}$ para amenização dos custos de transação (explicados adiante).

Porém, ao contrário do senso comum, essa ameaça da automação laboral não se limita a atividades rotineiras. Em virtude dos avanços alcançados não apenas pelo segmento de Robótica, mas também pela Inteligência Artificial, Machine Learning, Deep Learning e muitos outros graus de tecnologias, as mesmas se tornaram capazes, até mesmo, de adentrar campos até então vistos como "intocáveis", tais como Medicina, Advocacia, Contabilidade, que apesar da complexidade intrínseca a essas profissões, parcela significativa das tarefas realizadas por seus profissionais seguem padrões repetitivos, tornando-as suscetíveis aos impactos da automação tecnológica, que seria capaz de assumir muitas de suas incumbências rotineiras, diminuindo drasticamente o quantitativo de trabalhadores necessários para a prestação dos mesmos serviços.

Veja, a título de exemplo de trabalhos intelectuais possivelmente ameaçados pela transformação da economia digital, o segmento jurídico, em especial, escritórios de advocacia.

Como se sabe, o século XXI trouxe sistemas de automatização que modificaram a rotina tradicional dos escritórios de advocacia, em um processo de transição para uma carreira cada vez mais digital. Inicialmente, essa tecnologia se limitava a tarefas simples e repetitivas, como o acompanhamento de prazos processuais e publicações. Com a evolução de softwares jurídicos,

10 Em virtude da rapidez desse processo, especialistas tem argumentado que, nesse cenário "pós-automação", os trabalhadores terão grande dificuldade para serem readaptados em novos postos de trabalho, pois esses exigirão formação, conhecimentos e habilidades específicas, que muitos dos trabalhadores que operavam máquinas e realizavam trabalhos repetitivos ou braçais, simplesmente não possuem.

11 Estudo do IBGE, divulgado em outubro de 2019, aponta que a renda média de 54 milhões de trabalhadores brasileiros, equivalente a $60 \%$ dos trabalhadores formais e informais, foi inferior a um salário mínimo por mês durante o ano de 2018. De acordo com o estudo, um dos principais motivos para o aumento da desigualdade é a crise econômica, que impacta mais gravemente a camada mais pobre da população (IBGE, [2019]).

12 Já experimentamos muitos dos reflexos dessa "estratégia" no contexto atual. A reforma trabalhista trouxe uma multiplicidade de modalidades contratuais eminentemente precárias, como forma de tentar fomentar a contratação e manutenção de postos de trabalhos. 
os mesmos começaram a auxiliar na elaboração de petições, procurações e contratos. A própria judicialização de processos pode ser visto como um marco dessa transformação de ferramentas tecnológicas adotadas por nosso sistema judiciário.

No entanto, esse cenário começa a ser drasticamente alterado com a evolução da inteligência artificial. $\mathrm{O}$ ano de 2017 corresponde a outro relevante marco, por ter sido o ano em que Baker \& Hostetler, um dos maiores escritórios americanos de advocacia, realizou a contratação de ROSS, considerado o primeiro "robô advogado" do mundo. Construído pela IBM, ROSS utiliza recursos de computação cognitiva e processamento de linguagem, que o torna capaz não apenas de compreender a linguagem humana, mas de utilizar a inteligência artificial para trazer respostas às perguntas apresentadas, formular hipóteses jurídicas, examinar milhares de documentos, monitorar sistemas legais, sistematizar informações por ordem de relevância etc. $\mathrm{Na}$ prática, "advogados perguntam questões jurídicas a ROSS em linguagem natural, assim como se conversassem com um colega humano, e a inteligência artificial as interpreta utilizando a lei, reúne provas, extrai interferências e responde rapidamente, de modo altamente relevante e baseado em evidências, com citações e análises.”(INSTITUTO DE ENSINO SUPERIOR, C2017).

ROSS, porém, não é uma anomalia. Já é possível identificar outros robôs advogados, atuando em distintos setores, como Jill Watson (também projetado pela IBM) ou mesmo ELI, o primeiro robô advogado do Brasil, desenvolvido pela startup Tikal Tech. A Justiça brasileira também tem adotado softwares desenvolvidos por cientistas de dados e profissionais do direito, capazes de otimizar informações e auxiliar o fluxo do judiciário. São robôs de inteligência artificial que recebem nome de Victor, Elis, Clara, Hércules entre outros.

Desse modo, o que se esperar dos próximos anos para o universo jurídico e, até que ponto, as novas ferramentas oriundas dessa transformação digital sem precedentes resultará na diminuição das vagas de trabalho para os profissionais desse campo?

Certamente não experimentaremos uma completa substituição da profissão de advogado por máquinas. Isso não ocorrerá, considerando que atos como se relacionar com clientes, negociar com a outra parte, comparecer aos tribunais aparentam está fora que é alcançável pela inteligência artificial, pelo menos por enquanto. No entanto, é possível argumentar que a medida que a computação cognitiva e automação jurídica evolui e desenvolve capacidades para realizar atividades jurídicas que vão além de serviços repetitivos, um de dois possíveis cenários serão experimentados: ou o quantitativo de advogados será mantido e esses experimentarão drástica redução das horas de trabalho ${ }^{13}$, ou as horas de trabalho serão mantidas e o quantitativo de advogados será reduzido.

Considerando nosso modelo econômico e o processo crescente de concentração de renda acompanhado de elevados níveis de desemprego e subemprego, todos os indicativos históricos apontam para a segunda opção, ou seja, uma redução nas contratações (minimizando os custos de transação). É possível prever uma tendência de redução de empregos, especialmente no quantitativo de vagas ocupadas por advogados no início de carreira. Isso porque, atualmente, muitos das tarefas

13 Estudo realizado pela McKinsey Global Institute (2017) concluiu que até 1/4 do trabalho realizado por um advogado pode ser igualmente realizado pelo uso de inteligência artificial já disponível. 
que eram realizadas por esses profissionais, como sintetizar informações, organizar e classificar documentos, realizar pesquisas normativas e jurisprudenciais, aplicar teses pré-elaboradas, preparar relatórios, além de diversas outras rotinas, já são desenvolvidos, inclusive de forma mais rápida e eficiente, por sistemas de inteligência artificial. Com o caminhar rumo a algoritmos avançados, análise de dados, computação em nuvem e outras ferramentas de otimização capazes de operar sem qualquer necessidade de interferência humana, postos de trabalho em escritórios de advocacia certamente serão impactados.

\section{A TEORIA DOS CUSTOS DE TRANSAÇÃO E SUAS INFLUÊNCIAS NO PROCESSO DE AUTOMAÇÃO DO TRABALHO}

A popular teoria dos custos de transação tem origem que remonta a década de 1930, tendo sido confeccionada por Ronald Coase, um teórico economista britânico vinculado a tradicional Universidade de Chicago, vencedor do Prêmio Nobel de Economia (1991) e autor da célebre obra "O Problema do Custo Social". Coase foi o responsável em alterar paradigmas de como a economia deve compreender os mercados. A longevidade de suas formulações são inquestionáveis sendo, até hoje, um dos trabalhos mais citado no campo da legislação econômica.

Foi no seu ensaio intitulado The Nature of the Firm, publicado em 1937 pela Revista Econômica da prestigiada London School of Economics (LSE) que Ronald Coase se distanciou da escola econômica neoclássica ao trazer para o centro de suas investigações sobre organizações aspectos como transações e benefícios (ALMEIDA, 2019, p. 47). Em síntese, a problemática de partida de Coase foi compreender os modos alternativos de organização empresarial, focando na decisão entre organizar transações dentro da empresa ou mediante empresas autônomas, ou seja, o que levaria uma firma a escolha entre contratar diretamente um empregado para produção de bens ou prestação de serviços ou optar por opções disponíveis no mercado capaz de oferecer o mesmo serviço (terceirização).

Apesar da problemática de Coase se referir as razões pelas quais empresas contratam ou terceirizam, uma adaptação de seus pressupostos teóricos-econômicos certamente pode ser utilizado para compreender o dilema das empresas entre manter empregos ou automatizá-los, conforme será exposto nos tópicos que seguem.

\subsection{Elementos nucleares da teoria dos custos de transação}

Como ponto de partida, Coase busca compreender três distintas formas de relacionamentos existentes entre o detentor do capital e a empresa. A primeira é a possibilidade da firma, a cada nova operação a ser realizada (aquisição de bens ou serviços), utilizar novamente o mercado. Um segundo aspecto refere-se a sua reflexão sobre os ajustes dos contratos realizados com fornecedores. Por fim, o dilema do detentor de capital entre produzir o produto/serviço diretamente ou terceirizar a produção do mesmo.

Conforme a teoria, a decisão eficiente precisa considerar além do custo da produção 
propriamente dito, os custos intrínsecos as transações necessárias para à realização da produção. São duas distintas etapas de um processo produtivo. Coase apresentou alguns desses custos que devem ser internalizados, como os custos relativos à negociação, elaboração e manutenção dos contratos para cada transação. Assim, os custos de transação surgem quando bens e serviços são negociados, mas esses não são custos referentes a criação desses, e sim despesas necessárias para concluir satisfatoriamente a transação. Por óbvio, existem transações que comportam cadeias mais simples, outras mais complexas que requerem a consideração de maiores fatores.

Nessa linha, uma adequada análise corporativa deve mensurar dois custos distintos, aquele dos produtos e serviços, mas também os dispêndios independentes considerados como custos de transação. Refinando a teorização de Coase e melhor adequando-a as ciências sociais, o economista americano e, assim como Coase, vencedor do Nobel de Economia (2009) Oliver E. Williamson (The Economic Institutions of Capitalism), também dividiu os custos de transação em três partes, que chamou de: i) Custos de informação (gastos referentes ao acesso à informação sobre os produtos e serviços negociados, a busca no mercado por opções); (ii) Custos de negociação (gastos relacionados ao processo de negociação do contrato); (iii) Custos de observação (gastos necessários para certificar que todas as condições estabelecidas no contrato sejam cumpridas).

Williamson dimensiona dois relevantes aspectos que atuam como pressupostos comportamentais das empresas, à luz da teoria dos custos de transação econômica. Trata-se da racionalidade limitada e do oportunismo. Ambos atuam como princípios nucleares para compreender o comportamento dos agentes em negociações.

Nessa perspectiva, racionalidade limitada corresponde ao fato de que os agentes não conseguem alcançar informações de forma completa, pois, não possuem um conhecimento absoluto e sim fragmentado a certos aspectos (uma visão oposta à abordagem neoclássica de que presume uma racionalidade plena no momento de decisão). Essa limitação cognitiva do conhecimento e a incapacidade de predizer todos os acontecimentos futuros que podem advir de uma transação, é intrínseca ao ser humano. O nível de racionalidade foi descrito por Williamson e, ao final, evidenciado que essa limitação racional tende a resultar em aumentos nos custos de transação dos contratos. Isso porque os agentes, por compreenderem que não conseguem prever todas as possibilidades futuras de um contrato, incluem clausulas de "salvaguardas" capazes de trazer maior segurança mais, ao mesmo tempo, alavancarem os custos de transação (NASCIMENTO, 2011).

A teoria considera também o oportunismo dos agentes, e seu comportamento egoísta na busca por para maximizar suas próprias vantagens sobre a outra parte. O oportunismo é pautado na assimetria de informações, sendo o reconhecimento de que um agente detém informação que outro não possui acesso e, para que possa desfrutar de vantagens, tais informações são escondidas, apresentadas de forma incompleta ou mesmo distorcidas. O oportunismo pode se manifestar por mentiras, trapaças, fraudes e outros aspectos maliciosos. Caso não ocorresse oportunismo, e as transações fossem guiadas por regras claras e estáveis, as clausulas contratuais refletiriam essa segurança. No entanto, a realidade é que toda transação ocorre experimentando certo nível de desconfiança comportamental dos agentes. Em decorrência desse mar de incertezas, surge à 
necessidade de formular precauções, clausulas contratuais que busquem restringir comportamentos oportunistas. Essas também contribuem para um aumento nos custos de transação.

\subsection{Automação do trabalho à luz da teoria dos custos de transação}

A teorização proposta por Coase e avançada por Williamson nos permite extrair relevantes correlações com o cenário que experimentaremos com o avançar da quarta revolução industrial. Se a teoria de Coase foi confeccionada centralizada nas opções entre empregar ou terceirizar, a sua "modernização" certamente significaria considerar uma nova opção de modelo organizacional do capital, pautado na robotização e na inteligência artificial. Uma nova opção que, com a agilidade do desenvolvimento tecnológico, torna-se cada vez mais acessível para as mais distintas organizações, seja para a realização de atividades extremamente complexas ou cotidianas.

Partindo do pressuposto de que a teoria dos custos de transação busca compreender as tendências nos processos de desenvolvimento, centralizada em uma análise comparativa entre as alternativas disponíveis de produção e a tentativa racional de minimização de seus custos, esse novo cenário tecnológico torna-se uma variável relevante.

Conforme sugere essa teorização econômica, mesmo que a produtividade de robôs fosse idêntica ao trabalho humano (a realidade indica uma superioridade produtiva consideravelmente superior alcançada pelas máquinas), e que os gastos na manutenção da automação equivalessem ao mesmo ônus financeiro de manter empregados humanos (sistemas legais com gastos proporcionais quanto às obrigações tributárias, direitos trabalhistas e encargos sociais), a automação do trabalho ainda assim equivaleria à escolha mais eficiente. Isso porque a automação implicaria em uma sensível redução dos custos oriundos do oportunismo (robôs são menos sucintos a "trapaça" do que empregados) como os gastos da racionalidade limitada (as informações que robôs possuem são mais fáceis de serem compreendidas em sua plenitude do que empregados). Nesse cenário, haveria uma redução de riscos e incertezas, o que significaria uma redução dos custos de transação da empresa.

A constatação da teoria dos custos de transação evidencia o tamanho da problemática da automação dos postos de trabalho nos próximos anos. Utilizando o ponto de vista da economia, mesmo em um cenário hipotético de equiparação de eficiência e produtividade (não corresponde a realidade), e em um contexto proporcional de encargos tributários e trabalhistas entre homem e máquina (não corresponde a realidade), ainda assim a decisão racional de uma organização seria investir na automação, pois a redução dos custos de transação (queda no oportunismo e racionalidade limitada) significaria uma redução dos gastos da empresa, tornando-a mais competitiva em comparação as concorrentes que favoreceram o trabalho humano.

Então, se essa é a realidade, o que podemos esperar dos próximos anos considerando que todo o conjunto de sistemas legais atuais estabelece um cenário ainda mais grave, ignorando aspectos como robotização, inteligência artificial, big data e novas formas de automação laboral?

\section{ANÁLISE ECONÔMICA DO DIREITO E O PODER OCULTO DOS INCENTIVOS}


As interações entre Direito e Economia foram responsáveis por forjarem o espaço para a chamada Análise Econômica do Direito (AED). Uma escola que introduziu elementos teóricos essenciais para o aperfeiçoamento dos arranjos jurídicos, recepcionando conceitos econômicos que, até então, eram negligenciados pelas ciências legais, como efetividade e racionalidade. Essa coordenação, entre distintos campos científicos, proporcionou pensar sobre o comportamento dos agentes econômicos, frente o sistema normativo de forma diferenciada, expandindo a compreensão referente o alcance das regras jurídicas, em especial no que diz respeito as suas verdadeiras consequências.

A AED corresponde a um movimento não, a uma escola. Esse não possui um corpus de pressupostos teóricos unificados (NASCIMENTO, 2011, p. 237). A heterogeneidade de suas abordagens experimentam as mais distintas variações e graus, a depender das correntes acadêmicas de interpretação e suas linhas de reflexão e pesquisas.

O denominador comum desse movimento teórico diz respeito as tentativas de diminuição do foço que separa a experiência jurídica da realidade. A proposição de visões mais pragmáticas é comumente adotada em seus estudos. Isso significa ir além da teoria legal ao conectar o direito a problemas concretos. Como ferramenta, tem se provado extremamente fluido e flexível, sendo empregada nos mais diversos ramos do Direito, auxiliando-o a confrontar distintos problemas jurídicos e avaliar a qualidade de instrumentos legais.

Esse método de releitura normativa, introduzida pela AED, pode ser interpretado como uma abordagem consequencialista que, mediante adoção de instrumentos da teoria econômica (pressupostos como escassez de recursos, racionalidade dos agentes, resposta a incentivos, eficiência, etc.), busca analisar os efeitos das normas sobre a sociedade, compreendendo como os mais distintos estímulos podem interferir nos comportamentos dos agentes sociais (GONÇALVES; BONAT, 2018, p. 389).

Para fins do presente estudo, vamos direcionar o foco para duas dessas premissas da ciência econômica: escolha racional e resposta aos incentivos.

Não é incomum encontrar a afirmação de que "a economia é, em essência, o estudo dos incentivos." (LEVITT; DUBNET, 2012, p. 30). Em síntese simplista, incentivos interferem no comportamento dos indivíduos, direcionando-os a fazer ou deixar de fazer algo. Afinal, os destinatários das normas correspondem a atores racionais, respondem aos incentivos na tentativa de otimizar os seus interesses pessoais. Para a teoria econômica, a escolha racional pressupõe que os agentes atuam de acordo com uma ponderação coerente entre custo e benefício, considerando as vantagens ou desvantagens, prêmios e punições impostas pelo sistema a sua volta, incluindo aqui o sistema jurídico.

No entanto, aqui se torna imperativo uma ressalva, no que diz respeito os perigos da criação de estruturas de incentivos. Devido a sua própria natureza, a adoção por sistemas legais desses instrumentos moduladores de condutas, precisa ser acompanhada de máxima cautela, buscando anteceder possíveis comportamentos bem como considerar as potenciais combinações entre causas e consequências, pois "uma mínima guinada pode produzir resultados drásticos e 
muitas vezes imprevisíveis.” (LEVITT; DUBNET, 2012, p. 33).

Utilizando como suporte a microeconomia clássica, a cientificidade da AED pode enfrentar esse perigo, tendo em vista que também detêm a capacidade de ser empregada para premeditar as consequências que modificações e reformas normativas possam vir a ter, compreendendo como aqueles afetados por determinada normatização podem responder aos estímulos e desestímulos presentes na norma jurídica (SZTAJN, 2005). Isso porque "as pessoas reagem às sanções, em grande parte, da mesma maneira como reagem aos preços, consumem menos produtos mais caros; logo, supostamente, elas reagem a sanções legais mais duras praticando menos a atividade sancionada." (NASCIMENTO, 2011, p. 237). Com isso, padrões de comportamento podem ser identificados e antecipados, possibilitando, até mesmo, estimar as chances que determinado fim almejado pela lei tem de ser eficientemente alcançado.

Como visto, a literatura daAED argumenta que pressupostos como a resposta aos incentivos e a escolha racional dos agentes podem ser utilizados no desenvolvimento de sistemas jurídicos e, por consequência, no design das normas tributárias, guiando os instrumentos reguladores, frutos das escolhas políticas e legislativas ${ }^{14}$, tornando-as mais eficientes e permitindo-as alcançar um mais adequado desempenho, conforme os fins desejados ${ }^{15}$.

Nessa linha de pensamento, é razoável afirmar que a racionalidade decisória é o fator de maior determinação das ações a serem tomadas por agentes do mercado e, por consequência, há um desprestígio a questões como justiça social, valorização do trabalho humano, combate as desigualdades ou proteção do trabalhador em face da automação. No mercado, consideram-se primordialmente fatores econômicos. A busca da maximização da eficiência impõe a lógica de que empresas irão manter postos de trabalho apenas se as utilidades frutos dessa escolha excederem os benefícios obtidos com as demais opções disponíveis, incluindo (mas não limitando) à automação desses postos.

Justamente por isso que, para que seja alcançada a elaboração de políticas públicas eficientes, torna-se imperativo compreender comportamentos e respostas das organizações econômicas nos mais distintos mercados. Isso porque, frente o pressuposto da racionalidade na decisão e busca por eficiência econômica, resta evidenciado que os agentes respondem aos incentivos, agindo com base nas informações disponíveis e nas consequências (custos-benefícios) de sua decisão, buscando as maiores vantagens no momento de suas escolhas.

Portanto, reconhecendo a relevância de pressupostos teóricos como custos de transação, racionalidade econômica e resposta aos incentivos, restam evidenciados que "a tributação pode ser compreendida como um custo de transação em sentido estrito, pois é um custo inerente à celebração

14 Deve-se entender que o sistema de preços corresponde ao grande incentivador de comportamento humano pois esse "reage a estímulos pecuniários, tendo em vista esta premissa: sendo os recursos econômicos escassos, a decisão será aquela que maximize o seu bem estar em face dos recursos de que dispõe. Isso faz do Direito um importante instrumento para algumas políticas públicas, em especial, aquelas que dependem de seu cumprimento para serem eficazes ou, ainda, por meio de mecanismos que garantam certa segurança e estabilidade ao sistema. [...] O Direito é, por excelência, um indutor de condutas." (PINHEIRO; SADDI, 2005, p. 17).

15 Conforme bem destaca Paulo Roberto Pimenta (2020, p. 08): “O dinheiro é o meio mais racional de orientação da conduta econômica. As suas funções econômicas, como medida de valor e de pagamento, meio de troca e meio de conservação de valor, fornecem à Administração possibilidades de orientação e formas de ação, funcionando, também, como instrumento de satisfação de necessidades e de planejamento.” 
de um negócio jurídico, influenciando assim o processo decisório dos agentes." (GONÇALVES; BONAT, 2018, p. 393). Além disso, também corresponde a custo de transação "as inseguranças decorrentes de um sistema tributário imperfeito e ineficiente que implicam em maior incerteza na contratação, portanto, em um custo de transação maior." (CALIENDO, 2009, p. 22). Justamente por isso torna-se imprescindível propor reflexões investigativas de como nosso sistema tributário pode influenciar a automação laboral provocada pela difusão da economia 4.0.

\subsection{A norma tributária indutora como possível mecanismo de proteção do trabalhador face à automação}

Preliminarmente, adequado reforçar que a ordem econômica estabelecida no desenho constitucional brasileiro é fundada em um modelo de livre iniciativa diferenciada, harmônico não com os ideários do liberalismo secular ${ }^{16}$, e sim com aspectos sociais-democratas de valorização do trabalho humano, nos termos previsto no Título VII, da Constituição Federal de 1988, designado de "Da Ordem Econômica e Financeira". É essa tensão entre dois valores historicamente antagônicos, bem como os demais princípios que integram esse título (como a existência digna a todos e justiça social), que evidenciam as características do modelo de livre-inciativa da Constituição brasileira. Uma ordenação em que os valores liberais e sociais são simbioticamente aproximados, cabendo ao Estado o papel de estabilização desses pilares da ordem econômica.

Esse modelo constitucional impõe, ao Estado, a incumbência de atuar como regulador econômico, intervindo moderadamente, quando de forma fundamentada, na atividade produtiva e no mercado (ALMEIDA, 2017, p. 282). Esse planejamento da economia, inserindo balizas racionais, está em contexto com um Estado dualista, que mesclou valores historicamente antagônicos, trazendo como paradigma um desenvolvimento econômico que apenas pode ocorrer quando o bem-estar social caminha ao seu lado. Efetivar essa harmonia entre os elementos integrantes da ordem jurídica traria como resultado aquilo que Habermas intitulou de Capitalismo Organizado, ou que Ricardo Sayeg chamou de Capitalismo Humanista.

A substituição do trabalho humano por robôs não mais se trata de uma questão fantasiosa, limitado ao cinema hollywoodiano. Trata-se de um processo que caminha a passos largos e resultará em graves impactos nos setores sociais, econômicos e fiscais. Para compreender melhor suas ramificações, vamos momentaneamente nos afastar de análises centralizadas na ameaça aos direitos sociais individuais que um vasto quantitativo de trabalhadores poderão enfrentar com essa transformação, e voltar nossa atenção tão somente à perspectiva econômico financeira que poderá desenrolar-se para os cofres públicos.

Para compreender a estimativa de desequilíbrio fiscal a médio e longo prazo, basta atentar para a simples correlação, no âmbito de receitas e despesas dos recursos públicos, que se faz presente no seguinte domino econômico: (I) a refreada financeira impacta, em primeiro lugar, no âmbito das despesas públicas. Isso porque, em um contexto de progressiva substituição do

16 O liberalismo secular pode ser centralizado no conceito de "mão invisível do mercado", introduzido por Adam Smith em sua obra Teoria dos Sentimentos Morais, escrito no século XVIII. 
trabalho humano por máquinas, o governo precisará injetar volume substancial de recursos para suprir o aumento dos gastos experimentado com a concessão de mais benefícios sociais (tais como seguro-desemprego e salário-família), possibilitando que pessoas possam sobreviver apesar da difusão de desemprego e subemprego. Como se sabe, tais cenários tornam uma população ainda mais dependente dos programas sociais financiados por recursos estatais; (II) Outra sequência diz respeito ao fato de que pessoas desempregadas enxugam, ao máximo, seu consumo de bens e serviços em tudo àquilo que não corresponde a primeira necessidade (alimentícios). $\mathrm{O}$ efeito cascata oriundo dessas mudanças nos hábitos de consumo traz, entre outros reflexos na economia, um imediato impacto sobre a arrecadação das receitas tributárias diretas e indiretas incidentes nos distintos segmentos da cadeia de produção, diminuindo severamente a arrecadação do governo; (III) Uma distinta implicação ocorrerá no fato de que nossa tributação é excessivamente atrelada ao vínculo de emprego humano. Como se sabe, sob a folha de pagamento incide vasto leque de tributos que vão desde múltiplas contribuições até o imposto de renda da pessoa física. Toda essa receita deixaria de ser recolhida pelo Estado, no momento em que mais se precisaria em virtude da diminuição da arrecadação sobre consumo (II) e o aumento de seus gastos com benefícios sociais (I).

É justamente frente a gravidade dessa situação que se torna constitucionalmente justificável a utilização das normas tributárias, na sua chamada função extrafiscal, como ferramenta de intervenção no domínio econômico, indo além do papel meramente arrecadatório de recursos para os cofres públicos, funcionando como espécie de fio condutor estatal, direcionando condutas dos contribuintes de forma a prestigiar valores constitucionais ${ }^{17}$.

Como se sabe, a função extrafiscal introduz um raciocínio distinto de manuseio do sistema tributário nacional, conduzindo o comportamento do contribuinte rumo a predeterminada direção. Adequado destacar que na Constituição brasileira, não é possível encontrar qualquer previsão literal acerca da extrafiscalidade tributária. No entanto, a mesma aparece implicitamente em múltiplos institutos jurídicos que evidenciam um papel além da tributação arrecadatória, "sobretudo no regramento de isenções, imunidades, contribuições parafiscais, empréstimos compulsórios, seletividade do IPI, progressividade" (BOCAFOLI, 2016, p.18) entre outros institutos do direito tributário também capazes de provocar comportamentos para prestigiarem valores constitucionais.

As normas tributárias indutoras podem empregar a função extrafiscal para fomentar ou desestimular os agentes e a forma como os mesmos atuam na atividade econômica. Em sua estrutura, uma norma tributária indutora pode operar por dois caminhos para obter a ação ou abstenção almejada. Seu caráter diretivo ocorre nas formas de benefícios premiais (indução positiva) ou repreensões negativas (indução negativa), como na atribuição de uma vantagem ou privação de algum benefício, ou mesmo imposição de uma desvantagem, a depender da conduta humana qual o ordenamento jurídico pretende alcançar ou evitar. Por exemplo, o direito à saúde

17 Contribuindo para as discussões acerca da finalidade extrafiscal dos tributos Valcir Gassen (2013, p. 250) relembra que "no Estado Constitucional, uma legitimidade normativo-institucional e uma outra, uma legitimidade substancial, vinculada ao cumprimento por parte do Estado de um conjunto de tarefas que são entendidas como essenciais à vida em sociedade e que justificam a sua intervenção e a sua existência, isto é, a perspectiva extrafiscal da matriz tributária também deve alcançar essa discussão.” 
"é diretamente contemplado mediante a aplicação de uma tributação mais forte com relação ao comércio de cigarros, desestimulando o seu consumo. O mesmo se aplica à educação, que pode ser fomentada por meio de isenções relativas aos livros." (BOCAFOLI, 2016, p. 18).

Desse modo, é inquestionável que a adoção de técnicas legislativas capazes de direcionar as atitudes de seus destinatários podem corresponder a importante feição da norma tributária, sendo comumente utilizada, por Estados modernos, como políticas estimulantes, harmônico a função promocional do Direito em assegurar o interesse público ${ }^{18}$.

Nesse ponto, é possível adentrar o imaginário jurídico proposto como objetivo nuclear desse breve ensaio acadêmico. Conforme a concepção de ordem econômica exposta, bem como considerando o papel extrafiscal da norma tributária, é razoável afirmar que a normatização tributária pode ser utilizada como ferramenta de intervenção por indução, assegurando que, nesse contexto ascendente de automação nas atividades laborais, o equilíbrio entre a livre iniciativa e a valorização do trabalho humano ocorra de forma adequada aos valores jurídicos presentes na Constituição de 1988.

Diante da realidade de esvaziamento do mercado de trabalho em uma economia cada vez mais digital e robotizada, torna-se cada vez mais urgente que um novo sistema tributário venha a ser construído. Uma sofisticada reestruturação, adotando a extrafiscalidade tanto como parâmetro para a elaboração de critérios especiais na edição de normas tributárias, mas também como instrumento fiscal para promoção de objetivos socioeconômicos, norteando as escolhas dos agentes como forma a coibir um processo de automação conflituosa com princípios constitucionalmente reconhecidos, como de valorização do trabalho humano e justiça social, que devem atuar como bússola moral de nossa livre iniciativa.

No que diz respeito à possibilidade de tributação de robôs, grandes dilemas e debates certamente surgirão em breve. Até o presente momento, não há indícios que nenhuma nação tenha estabelecido concretamente uma tributação sobre robôs (BOTTONE, 2018, p. 18), porém, certamente corresponderá a um campo que possibilitará o desenvolvimento de empolgantes análises acadêmicas.

Por exemplo, aspectos como progressividade e seletividade poderiam atuar como interessantes ferramentas de indução ou desestímulo comportamental. Alíquotas progressivas, estruturadas em distintos coeficientes, ${ }^{19}$ permitiriam regular a carga tributária à medida que empresas realizem determinados graus de comportamentos, majorando ou minorando de acordo com a postura do contribuinte e a necessidade estatal de proteção do mercado de trabalho (considerando aspectos sociais, regionais, fiscais e econômicos). Aliado a observância da capacidade contributiva,

18 Neste ponto, imprescindível relembrar que a adoção da extrafiscalidade desperta problemas, como a sua possível afronta ao ideário de neutralidade tributária que "[...] tenciona-se a manter o equilíbrio da economia, de forma que ela seja afetada o menos possível pela tributação. Ao implementar uma política, o Estado deve fazê-lo influenciando o mínimo possível a tomada de decisões pelos agentes econômicos e o sistema de formação de preços, bem como gerando menos efeitos negativos para a sociedade, sob pena de tornar ineficiente o sistema econômico. A tributação deve ser utilizada visando a menor interferência nas escolhas dos agentes econômicos e o menor impacto na formação dos preços." (GONÇALVES; BONAT, 2018, p. 395).

19 Um modelo similar ao que já é utilizado em propriedades rurais, cuja a "a alíquota deste imposto leva em consideração, por ter finalidade também extrafiscal, o tamanho da propriedade, além do coeficiente de utilização e produtividade." (ICHIHARA, 2015, p. 232). 
poderia ser desenvolvida uma tributação capaz de evitar inequidades óbvias (como a incidência de uma mesma alíquota independente do tamanho das empresas, setores de exploração econômica, nível de automação, etc.); Esses e outros relevantes aspectos da teoria do direito fiscal e tributário evitarão a criação de um problema maior do que uma solução.

Considerando o modelo de tributação brasileira, a formulação desse novo arranjo da base tributária deverá ocorrer nos níveis municipais, estaduais e federais, incluindo reformas não apenas no âmbito da legislação ordinária e complementar, mas, possivelmente, para adequadamente sanar esse descompasso existente entre a realidade dos novos modelos de negócios com o modelo fiscal e tributário, será necessário um processo aprofundado que infiltre, inclusive, no próprio texto constitucional.

\section{CONCLUSÃO}

Conforme evidenciado, as formalizações de contratos de trabalho são, por uma perspectiva de racionalidade econômica, interpretadas como custos. Esses custos repousam não apenas no fato de que os mesmos são vinculados a um plexo de obrigações jurídicas (encargos) em campos sociais, trabalhistas e tributários, mas também pelo fato de que tais contratos são pactuados com humanos. Isso implica quantificar o impacto econômico oriundo de outros aspectos intrínsecos a condição humana dos trabalhadores, como o fato de que esses adoecem e falta o trabalho, precisam ser temporariamente substituídos durante as férias ou quando se tornam pais, necessitam de finais de semana e feriados, realizam greves, enfrentam problemas familiares que afetam sua produtividade, acessam o judiciário para reclamar direitos e diversos outros aspectos economicamente relevantes que correspondem a significativos dispêndios e que, em um contexto de análise econômica da empresa, são interpretados como custos de transação.

Desse modo, partindo de uma razão justificadora estritamente financeira, a automação do trabalho significa não apenas eliminar os custos oriundos dos sistemas jurídicos tributários, trabalhistas e sociais, mas também eliminar o impacto econômico fruto da condição "humana" do trabalho, que serão enxutos quando o mesmo passa a ser executado por máquinas.

É imprescindível que o Estado reconheça seu dever de estabelecer um redirecionamento de comportamentos dos agentes econômicos, partindo da premissa de coordenação entre escassez de recursos e escolha racional dos agentes ${ }^{20}$. Em um contexto de recursos finitos, é razoável presumir que os agentes, considerando o conjunto de oportunidades (opções) a sua volta, tendem a tomar decisões baseadas nos incentivos existentes em cada uma das alternativas postas a sua disposição, com uma propensão maior aquelas opções que lhe tragam os maiores benefícios e, ao mesmo tempo, se afastando daquelas que lhe acarretem mais graves prejuízos. Ou seja, buscam maximizar sua utilidade, de modo a alcançar maior satisfação pessoal, experimentando o menor

20 Paulo Caliendo $(2009$, p. 21) esclarece que "A teoria dos custos de transação tem como pressupostos teóricos a ideia de racionalidade limitada, complexidade e incerteza, oportunismo e especificidade de ativos. A teoria parte do pressuposto de que os agentes econômicos são racionais, porém não detém todos os elementos para uma decisão racional [...]. Outro pressuposto é que não há como o mercado evitar a presença de comportamentos antiéticos em uma negociação, $[. .$.$] denominado de oportunismo.”$ 
ônus possível ${ }^{21}$.

Considerando esse contexto, a tributação pode atuar como instrumento de regulação dos agentes econômicos, trazendo parâmetros que assegurem que o processo de difusão da automação ocorra de modo harmonioso com os demais valores constitucionalmente consagrados. Todavia, esse uso da tributação está vinculado ao desenvolvimento de um novo design para o nosso sistema tributário que, tendo sido confeccionado ainda na década de 1960, encontra severas dificuldades para se adequar a um mercado dominado por ativos incorpóreos e tecnologias que evoluem a uma velocidade sem precedentes. Justamente por isso que, conforme já apontava Agostinho Toffoli Tavolaro duas décadas atrás, é imperativo que "qualquer que seja o sistema adotado face a esse desafio, deve apresentar flexibilidade suficiente que lhe permita adequar-se a futuros desenvolvimentos tecnológicos" (TAVOLARO, 2000, p. 45).

Essa certamente não se trata de um dilema Shakesperiano em que seria adequado parafrasear Hamlet em sua incerteza (tributar ou não tributar, eis a questão), pois, para a criação de um sistema verdadeiramente justo, a decisão não diz respeito a "se" devemos tributar automação. Não há dúvida que, considerando as suas consequências sociais e econômico-financeiras, políticas governamentais e a construção de novos arranjos tributários invariavelmente deverão levar a esse resultado. A verdadeira questão, que aqui se coloca aos juristas, é "como" e "quando" deveremos, como sociedade, dar esse passo.

\section{REFERÊNCIAS}

ALMEIDA, Saulo Nunes de Carvalho. A teoria dos jogos e a sua influência sobre a litigância e o judiciário trabalhista. In: SILVA FILHO, Arnaldo Coelho da; ARAÚJO, Maria Lírida Calou de Mendonça; OLIVEIRA JÚNIOR, Vicente de Paulo Augusto de (org.). O poder judiciário em evidência. Rio de Janeiro: Lumen Juris, 2017. p. 279-298.

ALMEIDA, Saulo Nunes de Carvalho. Racionalidade econômica da empresa e suas influências no meio ambiente do trabalho. Revista de Direito Empresarial, Florianópolis, ano 16, n. 2, maio/ago. 2019.

BADENHAUSEN, Kurt. As 100 marcas mais valiosas do mundo em 2019. Forbes, [s. 1.], 22 maio 2019. Disponível em: https://forbes.com.br/principal/2019/05/as-100-marcas-maisvaliosas-do-mundo-em-2019/. Acesso em: 10 jul. 2020.

BOCAFOLI, Amarilis Inocente. Extrafiscalidade e princípio da igualdade tributária: compatibilidade e confronto com limites do poder de tributar. Revista FMU Direito, São Paulo, ano 26, n. 38, 2016.

BOtTONONE, Germana. A Tax on Robots? Working Papers, Roma, n. 3, set. 2018.

CALIENDO, Paulo. Direito tributário e análise econômica do direito: uma visão crítica. Rio de Janeiro: Elsevier, 2009.

21 Adequado complementar, porém, que a ciência econômica considerada "a limitação da racionalidade dos indivíduos: afirmar que a escolha é racional não significa que os indivíduos sejam completamente racionais ou que sua decisão será a mais coerente sob o ponto de vista coletivo, mas sim que eles almejam o resultado que lhes propicie mais utilidade consoante suas concepções pessoais, de acordo com as informações que possuem." (GONÇALVES; BONAT, 2008, p. 389). 
GASSEN, Valcir. Matriz Tributária: Uma perspectiva para pensar o Estado, a Constituição e a Tributação no Brasil. Revista dos Tribunais, Rio de Janeiro, v. 935, set. 2013.

GONÇALVES, Oksandro Osdival; BONAT, Alan Luiz. Análise Econômica do Direito, Incentivos Fiscais e a Redução das Desigualdades Regionais. Revista Jurídica da Presidência, Brasília, v. 20, n. 121, jul./set. 2018.

HARARI, Yuval Noah. Sapiens: uma breve história da humanidade. São Paulo: Coleção L\&PM, 2015.

IBGE. Pesquisa Nacional por Amostra de Domicílios Contínua: PNAD contínua. Rio de Janeiro: IBGE, [2019]. Disponível em: https://www.ibge.gov.br/estatisticas/sociais/ trabalho/17270-pnad-continua.html. Acesso em: 10 nov. 2019.

ICHIHARA, Yoshiaki. Direito tributário. 19. ed. São Paulo: Atlas, 2015.

INSTITUTO DE ENSINO SUPERIOR - . . Ross, o primeiro robô advogado do mundo.

Teresina: ICEV, (C2017. Disponível em: https://www.somosicev.com/blogs/ross-o-primeiro-roboadvogado-do-mundo/. Acesso em: 20 jun. 2020.

LAMFO - LABORATÓRIO DE APRENDIZADO DE MÁQUINA E ORGANIZAÇÕES. Automation Jobs. Disponível em: https://lamfo.shinyapps.io/automacao/. Acesso em: 20 maio 2020 .

LEVITT, Steven; DUBNER, Stephen. Freakonomics: o lado oculto e inesperado de tudo que nos afeta. Rio de Janeiro: Elsevier, 2012.

MCKINSEY GLOBAL INSTITUTE. A future that works: automation, employment, and productivity. 2017. Disponível em: https://www.mckinsey.com/ /media/mckinsey/featured $\% 20$ insights/Digital\%20Disruption/Harnessing\%20automation $\% 20$ for $\% 20 \mathrm{a} \% 20$ future $\% 20$ that $\% 20$ works/MGI-A-future-that-works-Executive-summary.ashx. Acesso em: 10 jun.2020.

NASCIMENTO, Fábio Severiano do. Algumas contribuições da análise econômica do direito no estudo da tributação. Revista de Direito da Cidade, Rio de Janeiro, v. 3, n. 1, p. 232-260, 2011.

PIMENTA, Paulo Roberto Lyrio. Direito tributário ambiental. Rio de Janeiro: Forense, 2020.

PINHEIRO, Armando Castelar; SADDI, Jairo. Direito, economia e mercados. Rio de Janeiro: Elsevier, 2005.

SCHWAB, Klaus. A quarta revolução industrial. São Paulo: Edipro, 2016.

SZTAJN, Rachel. Law and Economics. In: ZYLBERSZTAJN, Décio; SZTAJN, Rachel. Direito e Economia: análise econômica do direito e das organizações. Rio de Janeiro: Elsevier, 2005. p. 74-83.

TAVOLARO, Agostinho Toffoli. Globalização e o direito no século XXI. Revista Tributária e de Finanças Públicas, Rio de Janeiro, v. 35, nov. 2000.

TELECO. Carga tributária. 2020. Disponível em: https://www.teleco.com.br/tributos.asp.

Acesso em: 10 jul. 2020. 


\section{UNIVERSIDADE FEDERAL DO RIO DE JANEIRO - UFRJ. O futuro do emprego no}

Brasil: estimando o impacto da automação. 2019. Disponível em: http://labfuturo.cos.ufrj.br/wpcontent/uploads/2019/08/O-impacto-da-automa\%C3\%A7\%C3\%A3o-no-Brasil.pdf. Acesso em: 10 jun. 2020.

Como citar: ALMEIDA, Saulo Nunes de Carvalho. Inteligência artificial, robótica e o lado oculto de um futuro sem empregos: o inesperado papel da tributação de robôs à luz da análise econômica do direito. Scientia Iuris, Londrina, v. 25, n. 1, p. 29-48, mar. 2021. DOI: 10.5433/2178-8189.2021v25n1p29. ISSN: 2178-8189.

Recebido em 19/07/2020

Aprovado em 10/03/2021 